\title{
Projecting the global macroeconomic dynamics under high-end temperature scenarios and strongly nonlinear climate damage functions
}

\author{
D. V. Kovalevsky ${ }^{1,2}$, S. I. Kuzmina ${ }^{1}$, and L. P. Bobylev ${ }^{1,2}$ \\ Received 17 December 2014; accepted 18 December 2014; published 24 December 2014.
}

Projections of the gross world product (GWP) for the $21^{\text {st }}$ century are computed on a simple climate-macroeconomic model using different global mean surface air temperature projections provided by General Circulation Models (GCMs) as input data. Two alternative specifications of climate damage functions proposed by Nordhaus and Weitzman are considered. High uncertainty of long-term global macroeconomic dynamics with respect to the choice of climate scenarios and climate damage functions is revealed. Strong nonlinearity of the Weitzman function combined with the "worst-case" temperature scenario yields a very dramatic scenario of long-term global economic development. A high degree of uncertainty accompanying existing assessments of climate-socioeconomic projections urgently calls for more detailed and better justified estimations of anticipated climate damages at high temperature increases above pre-industrial level. KEYWORDS: climate change; economic growth; climate damage function; uncertainty.

Citation: Kovalevsky, D. V., S. I. Kuzmina, and L. P. Bobylev (2014), Projecting the global macroeconomic dynamics under high-end temperature scenarios and strongly nonlinear climate damage functions, Russ. J. Earth. Sci., 14, ES3001, doi:10.2205/2014ES000545.

\section{Introduction}

Climate mitigation policies are often being designed to meet certain measurable targets, e.g. a target of keeping the global warming below $2^{\circ} \mathrm{C}$ set in the Copenhagen Accord [UNFCCC, 2010]. Whether this $2^{\circ} \mathrm{C}$ threshold is firmly justified from the viewpoint of climate science or not (e.g. see a recent criticism in [Jaeger and Jaeger, 2011]), there is currently a growing concern that this mitigation target is unlikely to be met. Fundamental obstacles that put into question the "two-degree scenario" range from observed steady growth of consumption of fossil fuel resources [Voinov and Filatova, 2014 to various institutional barriers to efficient mitigation policies [Matveenko, 2010]. Meanwhile, discussions on a possible " $4{ }^{\circ} \mathrm{C}$ world" are becoming a hot topic [Anderson and Bows, 2011] Peters et al., 2013. At the same time, some recent studies suggest that socioeconomic impacts of even $2^{\circ} \mathrm{C}$ warming above the pre-industrial level would be much more adverse than it was previously thought [Mann, 2009, Smith et al., 2009. All this makes the more

\footnotetext{
${ }^{1}$ Nansen International Environmental and Remote Sensing Centre (NIERSC), St. Petersburg, Russia

${ }^{2}$ Nansen Environmental and Remote Sensing Center (NERSC), Bergen, Norway
}

Copyright 2014 by the Geophysical Center RAS.

http://elpub.wdcb.ru/journals/rjes/doi/2014ES000545.html reliable assessment of socioeconomic impacts of high-end climate scenarios (that are the "worst-case" scenarios provided by state-of-the art General Circulation Models (GCMs)) a task crucial for the design of efficient climate adaptation and mitigation policies.

GCMs and regional climate models provide as their outputs global and regional climate projections [Bobylev et al., 2003 IPCC, 2007, 2013. Shkol'nik et al.,2012 Stroeve et al., 2012 Volodin et al., 2008 that can further serve as inputs for impact assessment studies. Particularly, this sequential scheme is adopted in the present paper. It should be noted in this respect that many of Integrated Assessment models (IAMs) developed in economics of climate change are essentially the models of coupled climate-socioeconomic dynamics in which both climate and socioeconomic projections are instead computed self-consistently [Hasselmann, 2013 Nordhaus, 2008. Porfiryev, 2008 Stern, 2007. Weber et al., 2005, although some IAMs still follow the sequential architecture [Cápellan-Pérez et al., 2014].

Any projections of global climate-socioeconomic system dynamics are inevitably uncertain [Rovenskaya, 2010, Stern, 2007, and there is a general perception among experts in economics of climate change that uncertainties related to socioeconomic systems and quantification of climate impacts on them are much higher than uncertainties related to the current state of climate science and climate modelling. Particularly, the climate damage functions that are the building blocks of nearly all IAMs are perceived by many experts as a 
"weak link" and one of the most important sources of uncertainty in modelling exercises of this kind [Nordhaus, 2008 Ortiz and Markandya, 2009. Pindyck, 2013, ${ }^{3}$

In the current paper we compute projections of the gross world product $(\mathrm{GWP})$ for the $21^{\text {st }}$ century on a simple climate-macroeconomic model using different available climate projections provided by GCMs as input data. We provide computations for two alternative specifications of climate damage functions recently proposed by Nordhaus 2008 and Weitzman 2012 and thus address a question of sensitivity of projections of climate-socioeconomic system dynamics to the choice of climate damage functions. The same two climate damage functions have been recently intercompared in [Wouter Botzen and van den Bergh, 2012 for a different economic modelling framework, i.e. for the DICE model of William D. Nordhaus [Nordhaus, 2008, and different questions have been addressed (in [Wouter Botzen and van den Bergh,2012 optimal mitigation policy has been assessed for two alternative climate damage functions, while we are studying "business-as-usual" scenarios with no mitigation).

The paper is organized as follows. In Sec. 2 we discuss GCM temperature projections used in the study. A simple climate-macroeconomic model using these GCM projections as input data is developed in Sec. 3 In Sec. 4 the two climate damage functions are specified, and model results are provided and discussed. Sec. 5 concludes.

\section{Temperature Projections From GCMs}

The continuing rise in the average temperature of Earth's climate system is referred to as global warming. Since the beginning of the $20^{\text {th }}$ century, the global air and sea surface temperature has increased about $0.8^{\circ} \mathrm{C}$. Each of the last three decades has been warmer than any preceding decade since 1850 [IPCC, 2013]. The long time scales and uncertainty associated with global warming has led analysts to develop scenarios of future environmental, social and economic changes. These scenarios can help governments understand the potential consequences of their decisions.

Estimates of impacts from anthropogenic climate change rely on projections from climate models. Climate model projections were summarized in the 2007 Fourth Assessment Report (AR4) by the Intergovernmental Panel on Climate Change (IPCC) [IPCC, 2007]. They indicated that during the $21^{\text {st }}$ century the global surface temperature is likely to rise a further 1.1 to $2.9^{\circ} \mathrm{C}$ for their lowest emissions scenario and 2.4 to $6.4^{\circ} \mathrm{C}$ for their highest.

Recent studies revealed that Earth continues to experience warmer temperatures than several decades ago. The past year was the ninth warmest year on record since 1880, continuing what appears to be a long-term global trend of rising temperatures. The ten warmest years have all oc-

\footnotetext{
${ }^{3}$ Problems related to parameterization of damages caused by natural hazards of various kinds are discussed in depth in [Rodkin and Pisarenko, 2008 Rovenskaya, 2010.
}

curred since 1998, and the last year that was cooler than average was 1976. The hottest years on record were 2005 and 2010 [Atkinson, 2013].

Coupled global climate models (CGCMs) are the major objective tools available to provide future climate projections based on physical laws that control the circulation and thermodynamics of the atmosphere, ocean, land and sea ice. Models continuously improve, representing more processes in greater detail. This implies greater confidence in their projections. Coordinated experiments, in which many climate models run a set of scenarios, have become the standard to produce climate projections. Those multi-model ensembles sample uncertainties in emission scenarios, model uncertainty and initial condition uncertainty, provide a basis to estimate projection uncertainties.

The most current generation of atmosphere-ocean GCM simulations has been recently completed for the Intergovernmental Panel on Climate Change (IPCC) in order to provide input to the IPCC Fifth Assessment Report (AR5) [IPCC, 2013. In this work we assess the future changes of the air temperature in the $21^{\text {st }}$ century using an ensemble of IPCC AR5 global climate models. The basic CMIP5 (Coupled Model Intercomparison Project, URL: http://cmippcmdi.llnl.gov/cmip5/) simulations to be considered in this work include two representative scenario experiments for the $21^{\text {st }}$ century: medium stabilization scenario RCP 4.5 and higher emission scenario RCP8.5. These two emissions scenarios correspond to a high and medium radiative forcing of +8.5 and $+4.5 \mathrm{~W} / \mathrm{m}^{2}$ in 2100 relative to pre-industrial levels. A business-as-usual economic projection implies a greater than RCP4.5 emission scenario. The results of five Earth System Models and GCMs participating in CMIP5 are analyzed in this study.

We have chosen the models which reasonably reproduce the present climate. Namely, the following CMIP5 models were used: 1) CCSM4 (USA); 2) HADGEM2-ES (UK); 3) HADGEM2-cc (UK); 4) MPI-ESM-MR (Germany); 5) MRICGCM3 (Japan) [Taylor et al., 2012.

We computed the global mean surface air temperature (SAT) projections (referred to below as just temperature projections) from GCM runs by averaging over the globe. The analysis was performed for each month for the period of 2006-2100, annual means were then computed. To facilitate intercomparison, all the data were interpolated to $2.5^{\circ} \times 2.5^{\circ}$ regular grid sets. In spatial averaging, the cosine of the central latitude of each grid box was applied as a weighting factor.

Thus, totally ten projections of global mean SAT were computed by us for two RCPs (RCP4.5 and RCP8.5) and for five different GCMs (see Figure 1 1 ). Then two temperature projections have been selected from ten for our assessment of global macroeconomics impacts of climate change in the $21^{\text {st }}$ century (Figure 1 b).

\section{The Climate - Macroeconomic Model}

As a basis for our simple global climate-macroeconomic model we choose a standard AK model of endogenous eco- 
nomic growth [Barro and Sala-i-Martin, 2003]. We first briefly describe the standard model (yet without climate impacts) and then supplement it with certain climate damage function.

The production function of the global economy (i.e., the GWP) in the standard AK model is chosen to be linear in capital,

$$
Y=A K
$$

where $Y$ is the (global) output, $A$ is the technology level, and $K$ is the (global) stock of capital understood in a broad sense (including physical, human and social capital).

The capital dynamics equation is

$$
\dot{K}=s Y-\delta K
$$

where $s$ is the savings rate and $\delta$ is the depreciation rate. By substituting Eq. (1) into Eq. 22 we get a linear ODE

$$
\dot{K}=[s A-\delta] K
$$

The solutions of the model grow exponentially in time:

$$
\begin{aligned}
& K(t)=K_{0} \exp \left[\gamma_{0} t\right] \\
& Y(t)=Y_{0} \exp \left[\gamma_{0} t\right]
\end{aligned}
$$

where $K_{0}$ and $Y_{0}$ are initial values of capital and output, respectively, and

$$
\gamma_{0}=s A-\delta
$$

is the growth rate of the economy.

We now introduce climate impacts into the model. Assuming that a fraction $d(T)$ of global output dependent on the current state of global climate system (represented in our model by global mean surface air temperature $T(t)$ known from GCM simulations, see Sec. 2 is lost because of adverse impacts of anthropogenic climate change, we get the effective global output $Y_{\text {eff }}$ in the form

$$
Y_{\mathrm{eff}}(t)=(1-d(T(t))) A K(t)
$$

The function $d(T)$ appearing in Eq. (4) is called the climate damage function. Two of many proposed alternative forms of climate damage functions will be specified below in Sec. 4 and it will be shown that long-term macroeconomic projections may be very sensitive to the form of $d(T)$.

Now $Y$ should be replaced by $Y_{\text {eff }}$ in Eq. 11, and we come to a modified capital dynamics equation taking into account the climate damage:

$$
\dot{K}=[(1-d(T(t))) s A-\delta] K
$$

Provided that temperature projections $T(t)$ are known from GCMs (Sec. 2), Eq. (5) can be solved in a closed form. The final result for effective output is provided by a formula

$$
\left.Y_{\text {eff }}(t)=(1-d(T(t))) Y_{0} \exp \left[\gamma_{0} t-s A \int_{0}^{t} d\left(T\left(t^{\prime}\right)\right)\right) d t^{\prime}\right]
$$

where integration over time should be performed numerically.
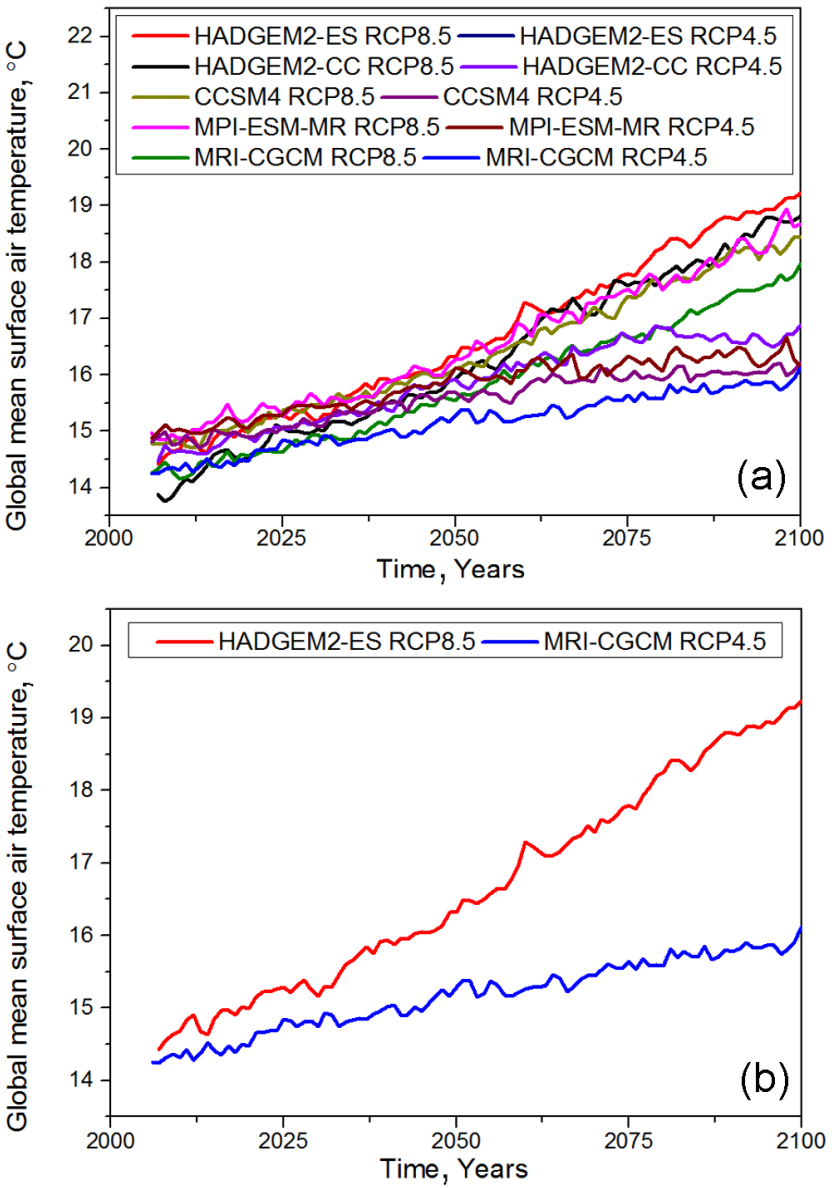

Figure 1. Global mean surface air temperature projections for the $21^{\text {st }}$ century computed for different RCPs and different GCMs (vertical axis $-{ }^{\circ} \mathrm{C}$ ): (a) ten temperature projections (two RCPs (RCP4.5 and RCP8.5), five GCM for each RCP) and (b) two temperature projections selected from ten for the assessment of global macroeconomics impacts of climate change in the $21^{\text {st }}$ century: the "best-case" projection (RCP4.5, MRI-CGCM model) and the "worstcase" projection (RCP8.5, HADGEM2-ES model).

\section{Macroeconomic projections for different climate damage functions}

To make quantitative macroeconomic projections in accordance with Eq. (6), we should specify values of model parameters and choose concrete parameterizations for climate damage functions.

With regard to macroeconomic parameters, we make a standard assumption about the depreciation rate $\left(\delta=0.05\right.$ year $\left.^{-1}\right)$ and also assume that in case of no climate impacts (baseline scenario) the global economy would grow at an annual rate of 2 percent $\left(\gamma_{0}=0.02\right.$ year $\left.^{-1}\right)$. In accordance with Eq. (3) this yields $s A=0.07$ year $^{-1}$.

We also adopt two alternative specifications for climate 
damage functions: a weakly nonlinear function

$$
1-d_{\mathrm{N}}(T)=\frac{1}{1+0.0028(\Delta T)^{2}}
$$

proposed by Nordhaus 2008, and a strongly nonlinear function

$$
1-d_{\mathrm{W}}(T)=\frac{1}{1+(\Delta T / 20.46)^{2}+(\Delta T / 6.081)^{6.754}}
$$

proposed by Weitzman 2012], $\Delta T$ being the temperature increase above the pre-industrial level. It should be noted that climate damage functions proposed by Nordhaus and Weitzman almost coincide for moderate temperature increases, but, in view of much stronger nonlinearity of the Weizmann function, the latter provides much more severe climate damages for high temperature increases than the Nordhaus function.

The numeric integration is performed in Eq. (6) from year 2012 to year 2100 for two alternative climate damage functions (Nordhaus - Figure 2a, Weitzman - Figure 2b) and three climate scenarios: the baseline scenario (no climate impacts, black curve on Figure 2 a, b), the "best-case" temperature projection (RCP4.5, MRI-CGCM, blue curve), and the "worst-case" temperature projection (RCP8.5, HADGEM2ES, red curve) - see Sec. 2 for details. The effective GWP is measured in constant USD 2005, and 55 trln USD 2005 is taken as its initial value for year 2012, in accordance with the World Bank data 4

The computed effective GWP projections are shown on Figure 2 The results of simulations can be summarized as follows. In the baseline scenario (no climate impacts, zero climate damages) GWP would reach 320 trln USD 2005 in 2100 , i.e. it would be 5.8 times higher than in 2012. For the "best-case" temperature projection (RCP4.5, MRI-CGCM) there would be moderate climate damages for the economy, and they would be almost identical for Nordhaus and Weizmann climate damage functions: the effective GWP would reach about 302 trln USD 2005 in 2100, i.e. it would be 5.5 times higher than in 2012. However for the "worstcase" temperature projection (RCP8.5, HADGEM2-ES, red curve) the climate impacts would be very different for Nordhaus and Weitzman climate damage functions. In case of Nordhaus function, the effective GWP would reach about 244 trln USD2005 in 2100, i.e. it would be 4.4 times higher than in 2012. In case of Weitzman function, the situation would be much worse: the effective GWP would be equal to 121 trln USD 2005 in 2100, i.e. it would be only 2.2 times higher than in 2012. Moreover, the effective GWP curve would no longer be monotonous in the latter case: the effective GWP would reach its maximum of 160 trln USD 2005 in 2076 (2.9 times higher than in 2012), and then it would start rapidly decreasing.

Therefore the results of our simulations (as of many other recent studies in the area of economics of climate change) reveal dramatic uncertainty of long-term global macroeconomic dynamics with respect to the choice of climate scenarios and climate damage functions.

${ }^{4}$ See the World Development Indicators at http://data. worldbank.org/products/wdi.
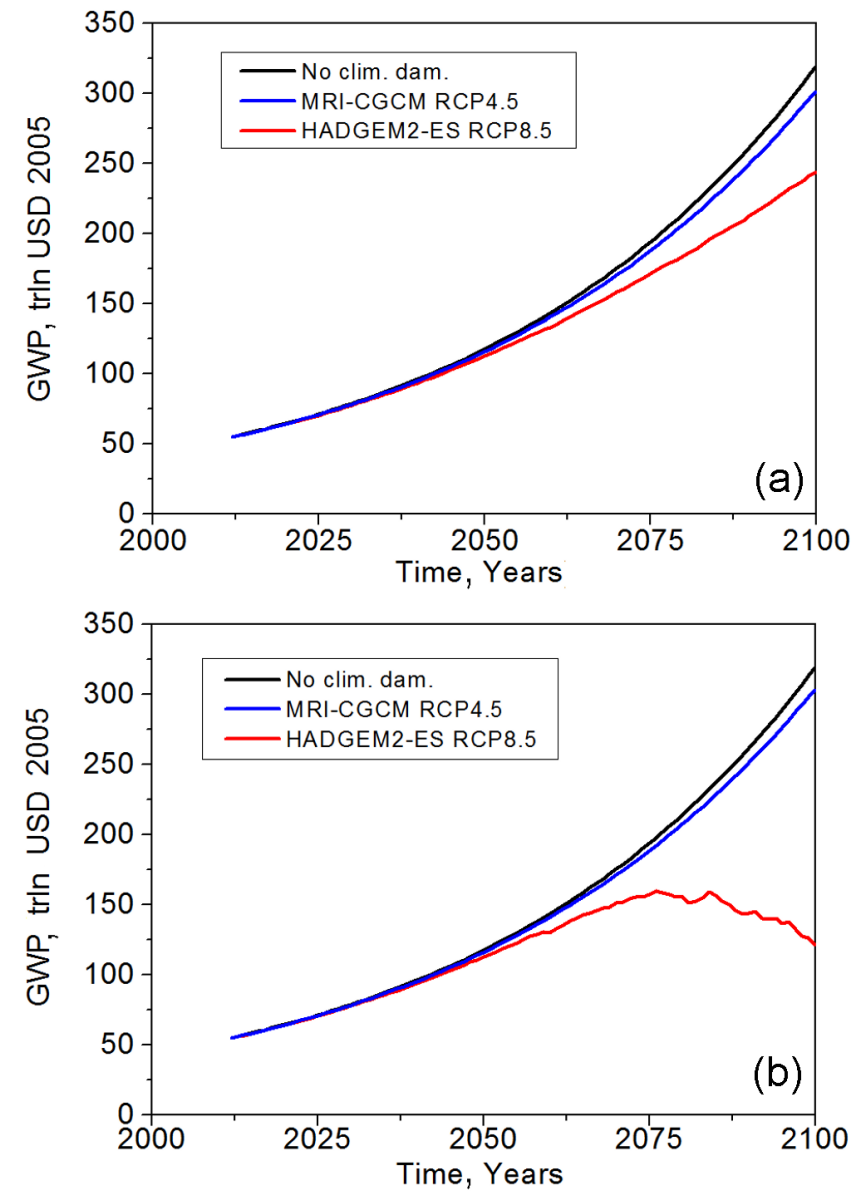

Figure 2. GWP projections for the $21^{\text {st }}$ century for different global mean surface air temperature projections and two alternative specifications of climate damage functions proposed by (a) Nordhaus 2008 and (b) Weitzman 2012.

\section{Conclusions}

In this paper we have estimated on a simple climatemacroeconomic model the projections of GWP by the end of the $21^{\text {st }}$ century under different climate scenarios for two different specifications of climate damage functions (a weakly nonlinear Nordhaus function and a strongly nonlinear Weitzman function). Strong nonlinearity of the Weitzman function combined with the "worst-case" temperature scenario yielded a very dramatic scenario of long-term global macroeconomic dynamics: a rather slow economic growth (as compared to other model setups considered) is stopped in about 2075 and then the global economy starts decaying. A very high degree of uncertainty accompanying assessment of climate-socioeconomic projections, particularly the uncertainty originating from poor knowledge of climate damage functions for high temperature increases, and pronounced nonlinearity of the coupled system under study at strong deviations from its current state, urgently calls for more detailed and better justified estimations of anticipated global, regional and sectorial climate damages. 
Acknowledgments. This study was supported by the Russian Foundation for Basic Research (Project No. 13-06-00368). The first author (D. V. Kovalevsky) also has a position at Saint Petersburg State University (St. Petersburg, Russia).

\section{References}

Anderson, K., A. Bows (2011), Beyond 'dangerous' climate change: emission scenarios for a new world, Philosophical Transactions of the Royal Society A, 369, 20-44, doi 10.1098/rsta. 2010.0290

Atkinson, N. (2013), Global temperatures continue to rise, Universe Today, January 17, 2013. URL: http://www. universetoday.com/99491/global-temperatures-continue-to-rise /\#ixzz31aPgJH3v

Barro, R. J., X. Sala-i-Martin (2003), Economic Growth, 2nd edition, The MIT Press, 672 pp.

Bobylev, L. P., K. Ya. Kondratyev, O. M. Johannessen (2003), Arctic Environment Variability in the Context of Global Change, Springer Praxis, 471 pp.

Cápellan-Pérez, I., M. González-Eguino, I. Arto, A. Ansuategi, K. Dhavala, P. Patel, A. Markandya (2014), New climate scenario framework implementation in the GCAM integrated assessment model. BC3 Working Paper Series 2014-04. Basque Centre for Climate Change (BC3). Bilbao, Spain, 46 pp.

Hasselmann, K. (2013), Detecting and responding to climate change, Tellus B, 65, 20088, doi 10.3402 /tellusb.v65i0.20088

IPCC (2007): Climate Change 2007: The Physical Science Basis. Contribution of Working Group I to the Fourth Assessment Report of the Intergovernmental Panel on Climate Change, Solomon, S., D. Qin, M. Manning, Z. Chen, M. Marquis, K. B. Averyt, M. Tignor, H. L. Miller (eds.). Cambridge University Press. $1056 \mathrm{pp}$.

IPCC (2013): Climate Change 2013: The Physical Science Basis. Contribution of Working Group I to the Fifth Assessment Report of the Intergovernmental Panel on Climate Change, Stocker, T. F., D. Qin, G.-K. Plattner, M. Tignor, S. K. Allen, J. Boschung, A. Nauels, Y. Xia, V. Bex, P. M. Midgley (eds.). Cambridge University Press. 1535 pp.

Jaeger, C. C., J. Jaeger (2011), Three views of two degrees, Regional Environmental Change, 11 (Suppl. 1), S15-S26, doi $10.1007 / \mathrm{s} 10113-010-0190-9$

Mann, M. E. (2009), Defining dangerous anthropogenic interference, Proceedings of the National Academy of Sciences of the USA, 106, 4065-4066, doi 10.1073/pnas.0901303106

Matveenko, V. D. (2010), Stimulating mechanisms in ecologically motivated regulation: will ecological policies in transition and developing countries become efficient? Journal of the New Economic Association, 8, 10-34.

Nordhaus W. D. (2008), A Question of Balance, Yale University Press, $234 \mathrm{pp}$.

Ortiz, R. A., A. Markandya (2009), Integrated Impact Assessment models with an emphasis on damage functions: a literature review. BC3 Working Paper Series 2009-06. Basque Centre for Climate Change (BC3). Bilbao, Spain, 32 pp.

Peters, G. P., R. M. Andrew, T. Boden, J. G. Canadell, P. Ciais, C. Le Quéré, G. Marland, M. R. Raupach, C. Wilson (2013) The challenge to keep global warming below $2^{\circ} \mathrm{C}$, Nature Climate Change, 3, 4-6, doi 10.1038/nclimate1783

Pindyck, R. S. (2013), Climate change policy: What do the mod- els tell us? Journal of Economic Literature, 51(3), 860-872, doi $10.1257 /$ jel.51.3.860

Porfiryev, B. N. (2008), The Economics of Climate Change, Ankil, 168 pp. (in Russian).

Rodkin, M. V., V. F. Pisarenko (2008), Damage from natural disasters: Fast growth of losses or stable ratio? Russian Journal of Earth Sciences, 10, ES1004, doi 10.2205/2007ES000267

Rovenskaya, E. (2010), Optimal economic growth under stochastic environmental impact: sensitivity analysis. In: Dynamic Systems, Economic Growth, and the Environment, J.C. Cuaresma et al. (eds.), Dynamic Modeling and Econometrics in Economics and Finance 12, Springer-Verlag, 79-107, doi 10.1007 /978-3-642-02132-9_5

Shkol'nik, 1. M., V. P. Meleshko, S. V. Efimov, E. N. Stafeeva (2012), Changes in climate extremes on the territory of Siberia by the middle of the 21st century: An ensemble forecast based on the MGO regional climate model, Russian Meteorology and Hydrology, 37(2), 71-84, doi 10.3103/S106837391202001X

Smith, J. B., S. H. Schneider, M. Oppenheimer, G. W. Yohe, W. Hare, M. D. Mastrandrea, A. Patwardhan, I. Burton, J. Corfee-Morlot, C. H. D. Magadza, H.-M. Füssel, A. B. Pittock, A. Rahman, A. Suarez, J.-P. van Ypersele (2009), Assessing dangerous climate change through an update of the Intergovernmental Panel on Climate Change (IPCC) "reasons for concern", Proceedings of the National Academy of Sciences of the USA, 106, 4133-4137, doi 10.1073/pnas.0812355106

Stern, N. (2007), The Economics of Climate Change: The Stern Review, Cambridge University Press, 712 pp.

Stroeve, J. C., V. Kattsov, A. Barrett, M. Serreze, T. Pavlova, M. Holland, W. N. Meier (2012), Trends in Arctic sea ice extent from CMIP5, CMIP3 and observations, Geophysical Research Letters, 39, L16502, doi 10.1029/2012GL052676

Taylor, K. E., R. J. Stouffer, G. A. Meehl (2012), An overview of CMIP5 and the experiment design, Bulletin of the American Meteorological Society, 93(4), 485-498, doi 10.1175/BAMS-D11-00094.1

UNFCCC. Conference of the Parties (COP) (2010), Report of the Conference of the Parties on its Fifteenth Session, held in Copenhagen from 7 to 19 December 2009. Addendum, Part two: Action taken by the Conference of the Parties at its Fifteenth Session, UN Office at Geneva, Switzerland. URL: http://unfccc.int/documentation/documents/advanced_search/ items/3594.php?rec $=$ j\&priref $=600005735 \#$ beg

Voinov, A., T. Filatova (2014), Pricing strategies in inelastic energy markets: can we use less if we can't extract more? Frontiers of Earth Science, 8, 3-17, doi 10.1007/s11707-013-0410-y. Volodin, E. M., V. Ya. Galin, N. A. Diansky, V. P. Dymnikov, V. N. Lykossov (2008), Mathematical modeling of potential catastrophic climate changes, Russian Journal of Earth Sciences, 10, ES2004, doi 10.2205/2007ES000231

Weber, M., V. Barth, K. Hasselmann (2005), A multi-actor dynamic integrated assessment model (MADIAM) of induced technological change and sustainable economic growth, Ecological Economics, 54, 306-327, doi 10.1016/j.ecolecon.2004.12.035

Weitzman, M. L. (2012), GHG targets as insurance against catastrophic climate damages, Journal of Public Economic Theory, 14(2), 221-244, doi 10.1111/j.1467-9779.2011.01539.x

Wouter Botzen, W. J., Jeroen C. J. M. van den Bergh (2012), How sensitive is Nordhaus to Weitzman? Climate policy in DICE with an alternative damage function, Economics Letters, 117(1), 372-374, doi $10.1016 /$ j.econlet.2012.05.032

L. P. Bobylev, D. V. Kovalevsky, S. I. Kuzmina, Nansen International Environmental and Remote Sensing Centre, 14th Line 7, office 49, Vasilievsky Island, 199034 St. Petersburg, Russia.

(dmitry.kovalevsky@niersc.spb.ru) 